Давыденко Ирина Геннадиевна

кандидат экономических наук, доцент кафедры «Финансы и кредит» Южного федерального университета

Рида Сабах Фадил Рида

магистрант кафедры «Финансы и кредит» Южного федерального университета

\section{АДАПТАЦИЯ ОПЫТА РАЗВИВАЮЩИХСЯ СТРАН ПО БОРЬБЕ С КОРРУПЦИЕЙ К УСЛОВИЯМ РЕСПУБЛИКИ ИРАК}

Davydenko Irina Gennadievna

PhD in Economics, Associate Professor, Finance and Credit Department, Southern Federal University

Rida Sabah Fadil Rida

Master's Degree student, Finance and Credit Department, Southern Federal University

\section{ADAPTATION OF ANTI-CORRUPTION PRACTICES OF DEVELOPING COUNTRIES TO THE ENVIRONMENT OF THE REPUBLIC OF IRAQ}

Статья посвящена изучению многолетнего опыта развивающихся стран по борьбе с коррупцией, которая оказывает разрушительное воздействие на систему государственного управления, социальную структуру и макроэкономическое развитие Для целей объективности понимания и интерпретации феномена коррупции в работе использован актуальный экономико-теоретический базис, позволяющий описать природу современных коррупционных моделей в развивающихся государствах мира. Систематизированы и упорядочены различные антикоррупционные стратегии, реализованные в таких странах (в частности, Синеапуре, Чили) и обладающие потенциалом адаптации и высокорезультативного применения к социально-экономическим и политическим условиям Республики Ирак посредством развития социальных, государственно-административных, государственно-правовых и международных институций. Наряду с институциональными "хабами», необходимыми для предупреждения и борьбы с коррупцией, обоснована практическая значимость цифровизации сектора государственных услуг как эффрективного информационно-технологического инструмента снижения уровня коррумпированности экономики.

\section{Ключевые слова:}

коррупция, теории коррупции, факторы коррумпированности экономики, антикоррупционные стратегии, антикоррупционные меры, индекс восприятия коррупции, развивающиеся страны, цифровизация.

The study investigates the longstanding anti-corruption practices of developing countries that have a devastating impact on public administration, social structure, and macroeconomic development. To understand and interpret the phenomenon of corruption objectively, the authors use the current economic and theoretical basis allowing them to describe the nature of modern corruption models in developing countries. The research systematizes and summarizes the various anti-corruption strategies implemented in these countries (in particular, Singapore, Chile) and having the ability to adapt efficiently to the social and economic and political conditions of the Republic of Iraq through the development of social, public administrative, state legal, and international institutions. Besides, the study substantiates the practical significance of the institutional hubs required to prevent and counteract corruption and the digitalization of the public services sector as an effective information technology tool to reduce the level of economic corruption.
\end{abstract}

Keywords: corruption, theories of corruption, economic corruption factors, anti-corruption strategies, anti-corruption measures, corruption perception index, developing countries, digitalization.

Перспективы развития фринансовой системы Республики Ирак обусловлены не только влиянием внешних и внутренних политических фракторов, но и уровнем обеспечения фринансовой безопасности, которая в условиях развивающихся стран во многом детерминируется степенью коррупции и коррумпированностью экономики. Так, с 2003 по 2016 г. общий доход консолидированного бюджета государства составил 850 млрд долл., при этом уровень коррупции за тот же период достиг около 400 млрд долл. [1].

Следует отметить, что, по оценкам агентства Transparency International, в Ираке наблюдается один из наиболее низких показателей восприятия коррупции (оценивается по 100-балльной шкале, где 0 - самый высокий уровень, 100 - самый низкий) за 2003-2018 гг. (по состоянию на июнь 2018 г.), что эмпирико-статистически подтверждает высокий уровень коррупции в стране. Из представленных на рисунке 1 фрактологических данных очевидно, что в Ираке - одной из развивающихся стран мира - на протяжении 15-летнего периода коррумпированность национальной экономической системы остается предельно высокой по сравнению с таковой других арабских государств. 


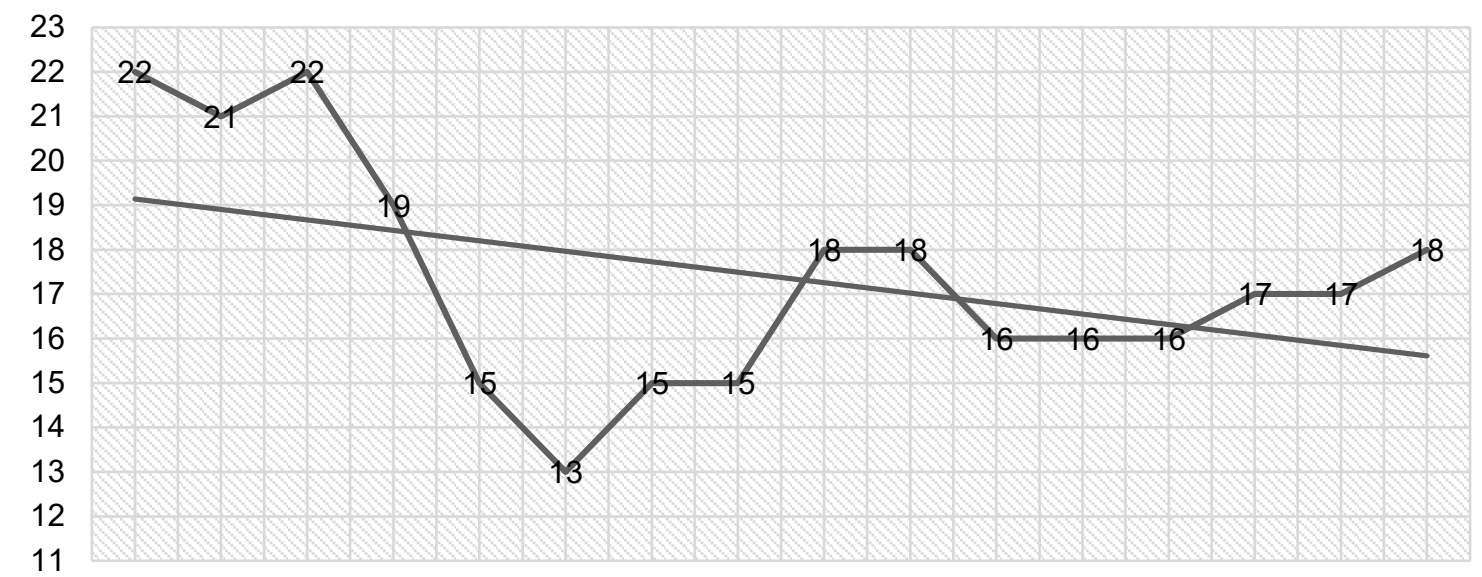

2003200420052006200720082009201020112012201320142015201620172018

—Индекс восприятия коррупции _-Линейная (Индекс восприятия коррупции)

Рисунок 1 - Динамика индекса восприятия коррупции в Ираке [2]

На основе сравнительного блицанализа уровня коррупции в ряде арабских стран можно констатировать, что в Объединенных Арабских Эмиратах индекс восприятия коррупции - один из наиболее высоких в современном арабском мире (71); при этом данный индикатор в Ираке (18) ниже, чем в ОАЭ, почти в 4 раза.

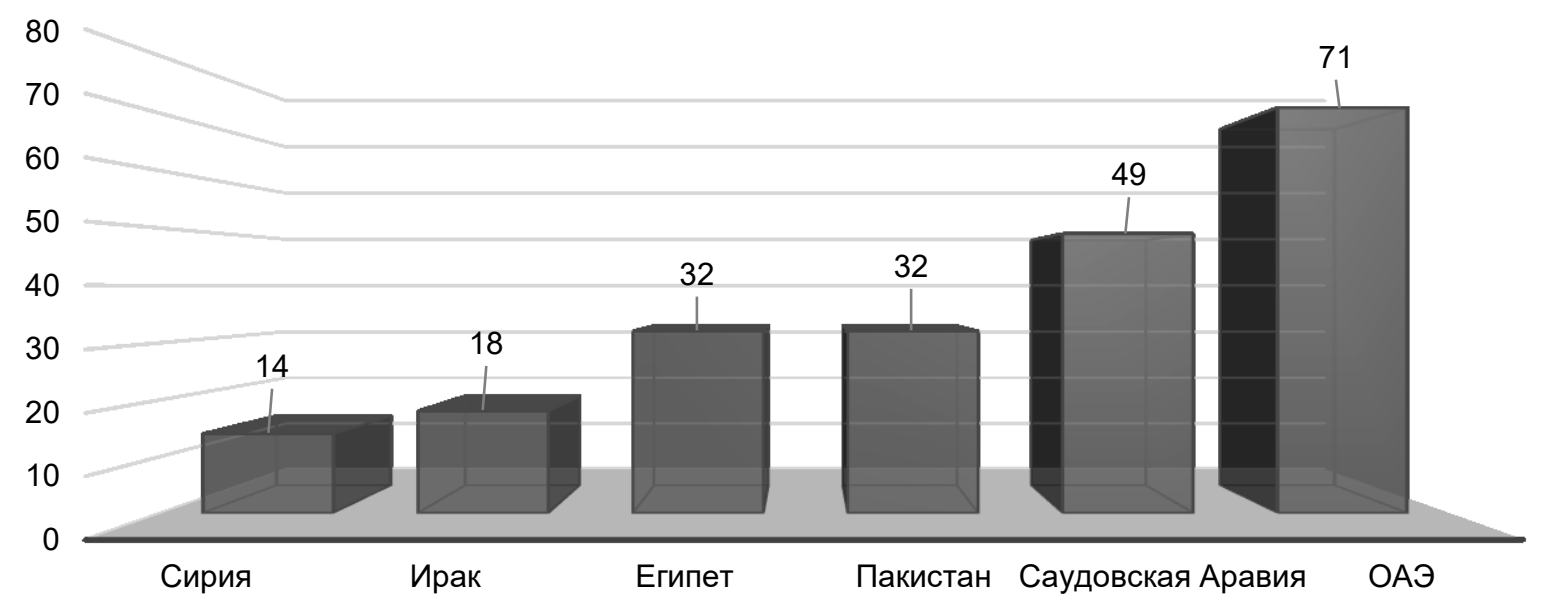

Рисунок 2 - Индекс восприятия коррупции в ряде арабских государств в 2018 г.

Указанные актуальные тенденции обусловливают необходимость исследования вопросов потенциала адаптации положительного опыта борьбы с коррупцией к условиям других развивающихся арабских государств, в частности Республики Ирак. Современные теории, описывающие коррупционные практики в развивающихся странах, могут оказаться полезны в понимании и интерпретации коррупции с учетом множества фракторов, ведущих к ее возникновению и распространению, в том числе в Ираке.

На основе проведенного нами блицанализа теоретических подходов к исследованию природы коррупции и ее последствий в развивающихся странах можно сделать следующие концептуально значимые выводы и обобщения.

Во-первых, представители так называемой «этической» теории обеспокоены распространением коррупции исключительно с морально-этической точки зрения и указывают на необходимость обучения и привития моральных ценностей еще не коррумпированным государственным чиновникам. Однако в качестве контраргумента действенности и продуктивности данного подхода другие исследователи отмечают, что трудно контролировать моральные установки человека, поскольку имеют место «невидимые» намерения и необъявленное морально-этическое поведение. В частности, на основании утверждения, представленного Г. Бекером, «что люди решают, совершать ли им преступление или нет, сравнивая [ожидаемые] выгоды и издержки от преступления» [3, p. 8], 
можно прийти к выводу, что любой коррупционер является корыстолюбивым человеком, его деятельность направлена на извлечение максимальных персональных доходов любой ценой, невзирая на нормы права и интересы других людей, т. е. нарушает нормы и права, и нравственности.

Во-вторых, с позиции последователей функциональной структурной теории коррупция способствует снижению напряженности и дает возможность для успешных действий экономических субъектов, поэтому сторонники данного направления считают, что коррупция играет позитивную роль в устранении глубокой бюрократической волокиты. Следует отметить, что приверженцы данного теоретического подхода дают идеологическое оправдание коррупции, аргументируя его тем, что совокупные общественные блага больше, чем коррупционный ущерб, следовательно, коррупционный акт экономически или политически эффективен, поэтому те, кто властвуют, не осуществляют коррупционную деятельность.

В-третьих, теория функциональной модернизации предусматривает, что коррупция в развивающихся странах представляет собой переходный этап, который можно преодолеть, т. е. негативные проявления коррупции, говоря образно, диагностируются как возрастающая боль, а не как смертельная болезнь. Сторонники данного концептуального подхода считают, что страны третьего мира, вероятно, последуют примеру развитых индустриальных обществ Западной Европы и Северной Америки, преодолевших состояние коррумпированности.

В-четвертых, теория зависимости базируется на том, что глобальная капиталистическая система искажает прогресс развивающихся социумов посредством навязанных коррупционных практик. Они позволяют Западу реализовывать свои интересы и ужесточать политический и экономический контроль над развивающимися государствами. Ось коррупции последних проходит через национально-политическую правящую элиту, которая совместно с внешними политическими силами стремится не допустить кристаллизации взглядов масс на существующую экономическую и социальную реальность. В связи с этим данная теория предусматривает, что коррупция в подобных обществах функционально связана с членами определенных социальных групп, поэтому синтаксически обусловлена как характером социальной структуры развивающихся стран, так и отношениями с развитыми партнерами.

Анализ концептуальных подходов к изучению разноуровневых коррупционных процессов и институционального инструментария борьбы с ними позволяет выявить слабую проработку рассматриваемой проблемы и констатировать фракт, что вопросы адаптации накопленного антикоррупционного опыта к условиям других государств, в частности Республики Ирак, остались в стороне от внимания исследователей.

В целях усиления аргументации выводов и обобщений по проблеме адаптации практики борьбы с коррупцией в развивающихся странах к условиям Республики Ирак необходима операционализация основного термина. Международные организации приводят собственные определения коррупции. Так, согласно Конвенции ООН против транснациональной организованной преступности 2000 г., ее смысловое значение полностью тождественно дефиниции взяточничества. Конвенция ООН против коррупции 2003 г. трактует коррупцию как действия, которые представляют собой ненадлежащее исполнение обязанностей, или как эффект принятия преимущества, предоставленного прямо или косвенно самому человеку или другому лицу [4].

Определение коррупции, сформулированное Transparency International - неправительственной международной организацией по борьбе с коррупцией, сводится к тому, что данный экономико-поведенческий феномен представляет собой злоупотребление полномочиями, возложенными на человека, в личных интересах. Следует отметить, что специалисты данного агентства выделяют коррупцию «по закону» и коррупцию «против закона» (рисунок 3), при этом между названными видами проводятся следующие различия. Так, первый тип известен и распространен как оплата объектов - взятки позволяют получить приоритет при оказании услуги от получателя взятки в соответствии с действующим законодательством. Второй вид отражает деятельность должностных лиц в общественном или частном секторе, политиков или государственных служащих, направленную на то, чтобы обогатить себя или родственников незаконным путем либо с помощью злоупотребления предоставленной властью.

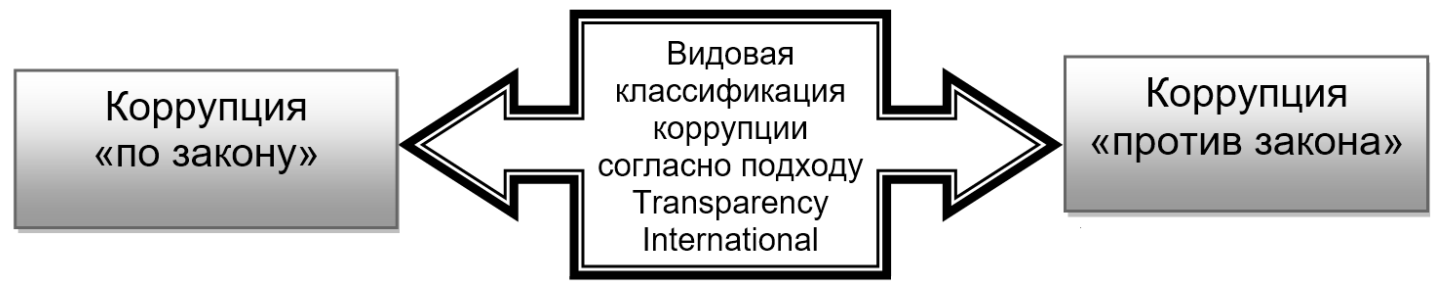

Рисунок 3 - Основные виды коррупции согласно типологии Transparency International 
Считаем целесообразным представить определение, сформулированное в Международном валютном фонде: коррупция представляет собой преднамеренную деятельность одного человека или группы лиц, связанной с другими, направленную на получение выгод от такой деятельности [5].

Опыт развивающихся стран по борьбе с коррупционными схемами и практиками позволяет выделить пять антикоррупционных стратегий институционального характера, которые при условии их комплексного применения демонстрируют эффрективность, в частности в Сингапуре и Чили.

\begin{tabular}{|c|c|c|c|c|}
\hline \multicolumn{5}{|c|}{ Антикоррупционные стратегии в развивающихся странах } \\
\hline $\begin{array}{c}\text { Выплата } \\
\text { адекватной } \\
\text { заработной платы } \\
\text { государственным } \\
\text { служащим }\end{array}$ & $\begin{array}{c}\text { Прозрачность } \\
\text { и открытость } \\
\text { государственных } \\
\text { расходов }\end{array}$ & $\begin{array}{c}\text { Устранение } \\
\text { бюрократической } \\
\text { волокиты }\end{array}$ & $\begin{array}{c}\text { Присоединение } \\
\text { к международным } \\
\text { соглашениям } \\
\text { по борьбе } \\
\text { с коррупцией }\end{array}$ & $\begin{array}{c}\text { Внедрение } \\
\text { цифровых } \\
\text { и интеллектуальных } \\
\text { технологий }\end{array}$ \\
\hline
\end{tabular}

Рисунок 4 - Антикоррупционные стратегии развивающихся стран

1. Для преодоления коррупционных практик необходимо выплачивать адекватные зарплаты государственным служащим и совершенствовать систему оплаты труда в государственном секторе. Если заработная плата в этом сегменте низкая, персонал может оказаться мотивирован на дополнение доходов «неофициальными» способами. Эмпирические исследования в развивающихся странах показали, что существует обратная зависимость между уровнем заработной платы в государственном секторе и «разгулом» коррупции. Следует отметить, что важнейшим инструментом ее сокращения в Сингапуре стало повышение окладов госслужащих. С 1972 г. для них действует программа по обеспечению «конкурентоспособности заработной платы и благоприятных условий труда» [6, с. 57].

2. В целях снижения коррупционной напряженности важно создать открытую систему государственных расходов. Так, некоторые страны прилагают усилия для обеспечения того, чтобы ресурсы использовались для удовлетворения общественных интересов. Чем прозрачнее процесс, тем меньше вероятность нарушений и злоупотреблений. При этом значимым условием считается способность граждан тщательно изучать финансовую деятельность правительства и обсуждать достоинства альтернативных направлений государственной экономической политики. Независимо от того, имеет ли страна активное гражданское общество, культура участия населения в финансовой жизни может быть важным компонентом стратегий, направленных на сокращение коррупции.

В 2017 г. лидерами рейтинга Transparency International по уровню коррупции (индексу восприятия коррупции) являются Новая Зеландия (89), Дания (88), Финляндия (85), Норвегия (85), Швейцария (85), Сингапур (84) [7]. Так, Новая Зеландия - одна из самых эффрективных стран в усилении прозрачности при подготовке государственного бюджета. Это стало возможным после принятия в 1994 г. закона о финансовой (бюджетной) ответственности [8], который установил стандарты открытости налогово-бюджетной политики, возложив на правительство ответственность за результаты деятельности в фискальной сфере [9, с. 81].

3. К сокращению уровня коррупции в условиях развивающихся стран способно привести уменьшение бюрократической волокиты и рутины в частности и развитие государственно-административной институции в целом. Например, в практике предпринимательской деятельности прослеживается стремление субъектов хозяйствования избавиться от многих ненужных правил, генерируемых бюрократической сферой, поскольку, чтобы начать бизнес, осуществить имущественную регистрацию, принять участие в торговле, требуется множество сертификатов и лицензий, иногда очень громоздких.

4. Поскольку коррупция в условиях глобализации экономики становится все более трансграничной, международно-правовой базис является важным инструментом антикоррупционной деятельности, доступным правительствам развивающихся государств. За прошедшее десятилетие глобально-правовая система значительно прогрессировала: в конце 2013 г. подавляющее большинство стран (140) приняло и ратифицировало Конвенцию ОЭСР по борьбе с взяточничеством, которая охватывает широкий круг вопросов, в том числе касающихся внутренней и внешней коррупции, вымогательства, превентивных мер в этой области, борьбы с отмыванием денег и конфликтов интересов. Однако, поскольку ООН не имеет исполнительных полномочий, эффективность указанного документа в качестве ресурса сдерживания коррупции будет в значительной степени зависеть от развития механизмов мониторинга на национальном уровне.

Следует особо отметить, что в настоящее время правительства развивающихся стран попрежнему используют политику двойных стандартов, предусматривающих уголовную ответственность за взяточничество в своей стране, но допускающих подкуп иностранных должностных лиц, не являющихся членами Организации экономического сотрудничества и развития. 
5. Одним из способов решения проблемы коррупции в развивающихся странах является использование различных легкодоступных населению и бизнесу информационно-цифровых технологий, которые стимулируют отношения между чиновниками и гражданским обществом, характеризующиеся автономией. В связи с этим Всемирная сеть оказалась эффективным инструментом для снижения уровня коррупции. В некоторых развивающихся государствах применение интернетпрограмм для содействия взаимодействию правительства с социумом и деловым сообществом было успешным при сборе налогов, государственных закупках и преодолении рутины. Возможно, один из важных источников коррупции в мире связан с осуществлением госзакупок. Объем потребления товаров и услуг со стороны государства может быть огромным: в разных странах данный показатель составляет от 5 до 10 \% ВВП. В связи с длительной историей взяточничества и сговора в данной сфере все большее число государств решили осуществлять процедуры торгов для обеспечения надлежащего уровня открытости, конкуренции и равных условий для поставщиков.

В целом система дистанционного предоставления государственных услуг и развитие цифровых технологий в государственном секторе позволяют практически свести на нет возможность коррупционных действий в рассматриваемой области. Наглядным и полезным является опыт Сингапура, где с конца 90-х гг. прошлого века функционирует интернет-портал для коммерческих предприятий. На сайте размещаются конкурсные требования, осуществляется подача заявок, сроки контролируются электронным способом, а результаты тендеров публикуются в открытом режиме.

Кроме того, интересен опыт Чили, где использованы новейшие технологии для создания одной из самых прозрачных систем государственных закупок в мире. Проект ChileCompra был запущен в 2003 г. как открытая для общественности электронная онлайн-программа закупок [10]. Данная инициатива завоевала положительную глобальную репутацию за прозрачность и эффективность 850 предприятий, осуществляющих закупочную деятельность. Кроме того, система обслуживает публичные компании и учреждения, а также отдельных граждан и на сегодняшний день является крупнейшим сайтом деловых операций в стране: в 2012 г. пользователи совершили 2,1 млн покупок и выставили счета в размере 9,1 млрд долл. США. Следует отметить, что по состоянию на март 2018 г. индекс восприятия коррупции в государстве находится на уровне 67.

Таким образом, ключевыми и экономически действенными антикоррупционными стратегиями институциональной направленности являются система оплаты труда в государственном секторе, обеспечение открытости и валидности информации в области государственных расходов, упрощение административно-разрешительных процедур в предпринимательской сфере, а также повышение уровня цифровизации сектора государственных услуг. При этом очевидно, что рассмотренные механизмы, реализуемые в развивающихся странах, не подлежат точному копированию и распространению для целей формирования антикоррупционной модели в Ираке. Однако описанный опыт позволяет выделить два государственно-политических направления в этой стране: предотвращение коррупции и борьба с ней.

В рамках первого направления осуществляется профилактическая политика. Широкий спектр мер данного антикоррупционного направления, используемых в современном Ираке, включает в себя в том числе политику образования и социального обеспечения.

Как указывалось, в антикоррупционной модели Сингапура во главу угла ставилась необходимость повышения уровня заработной платы государственных чиновников. Эту меру признают эффрективной и в Ираке, где реализуются социальные программы по обеспечению высокого уровня жизни государственных служащих, что является сдерживающим фактором для коррупции.

При построении профилактической антикоррупционной политики в Ираке учитывается опыт ряда развивающихся стран - реализуются упрощение административных процедур и ограничение количества документов, необходимых для получения услуги. Кроме того, ограничительной мерой выступает цифровизация государственного сектора, наиболее подверженного коррупции, в частности внедрение разноуровневых систем электронных платежей как альтернативы непосредственному приему штрафов и сборов государственными сотрудниками. В рамках развития данного направления правительство Ирака строит открытую и прозрачную с точки зрения информационной доступности государственную систему: процедуры и результаты административных контрактов публикуются в Интернете в электронном бизнес-центре.

В Ираке предусмотрена уголовная ответственность за коррупционные преступления, что вызывает необходимость совершенствования законодательной базы в данной сфере. Так, закон о Комиссии по добросовестности 2011 г. отождествляет коррупционные правонарушения с преступлениями против государственной безопасности и предусматривает тюремное заключение, высокие штрафы, конфискацию и реституцию. Для этих целей создан государственный орган, подчиняющийся премьер-министру, который посредством специальной резолюции назначает его членов. Эта государственно-правовая институция по примеру и опыту Сингапура наделена широкими полномочиями для проверки коррупционных случаев и сбора достоверных доказательств. Кроме того, публичные судебные коррупционные разбирательства и вынесенные судебные решения должны быть опубликованы, а расследование преступлений в этой области ведут 
несколько следователей, что обеспечивает прозрачность дознания и невозможность оказывать давление на его результаты.

Таким образом, на основе экономико-теоретического и сравнительного межстранового анализа реализуемых антикоррупционных стратегий в развивающихся странах в контексте авторского представления проблемы выделены ключевые социальные (система оплаты труда в госсекторе), государственно-административные (система разрешительно-запретительных процедур в сфере предпринимательства) и государственно-правовые (система уголовного наказания за коррупционные преступления) институции, участвующие в формировании антикоррупционной модели в Республике Ирак.

Изучение опыта функционирования сектора государственных услуг на основе дистанционных информационных технологий позволило сформулировать научно-содержательное и эмпирическое обоснование необходимости его цифровизации как эффективного информационно-технологического инструмента снижения уровня коррумпированности экономики.

\section{Ссылки и примечания:}

1. Первое инфрормационное агентство Ирака [Электронный ресурc] : официальный сайт. 2019. URL: https://www.alghadpress.com (дата обращения: 10.01.2019). На араб. яз.

2. Рисунки 1-3 составлены авторами на основе данных Центра антикоррупционных исследований и инициатив Transparency International [Электронный ресурс] : официальный сайт автономной некоммерческой организации. URL: https://www.transparency.org.ru (дата обращения: 10.01.2019).

3. Becker G. The Economics of Crime // Cross Sections. 1995. Vol. 12, no. 3. P. 8-15.

4. Конвенция ООН против коррупции [Электронный ресурс] : от 31 окт. 2003 г. // OOH : официальный сайт. 2019. URL: https://www.un.org/ru/documents/decl_conv/conventions/corruption.shtml (дата обращения: 10.01.2019).

5. Международный валютный фонд [Электронный ресурc] : официальный сайт. URL: https://www.imf.org (дата обращения: 10.01.2019).

6. Астафьева Е.М. Борьба с коррупцией в Сингапуре: стратегия и практика // Азия и Африка сегодня. 2016. № 1. С. 52-59.

7. TheWorldOnly [Электронный ресурс] : информационная инициатива по продвижению целей устойчивого развития : официальный сайт. URL: https://www.theworldonly.org (дата обращения: 10.01.2019).

8. Юридический департамент при парламенте Новой Зеландии [Электронный ресурс] : официальный сайт. URL: http://www.legislation.govt.nz/ (дата обращения: 10.01.2019).

9. Наумова Т. Теплый климат Новой Зеландии // Прямые инвестиции. 2012. № 6 (122). С. 78-81.

10. ChileCompra [Электронный ресурc] : официальный сайт. URL: https://www.chilecompra.cl (дата обращения: 10.01.2019).

\section{References:}

Astafieva, EM 2016, 'Fighting Corruption in Singapore: Strategy and Practice', Aziya i Afrika segodnya, no. 1, pp. 52-59, (in Russian).

Becker, G 1995, 'The Economics of Crime', Cross Sections, vol. 12, no. 3, pp. 8-15.

ChileCompra: official site 2019, viewed 10 January 2019, <https://www.chilecompra.cl>.

International Monetary Fund: official website 2019, viewed 10 January 2019, <https://www.imf.org>, (in Russian).

Legal Department at the Parliament of New Zealand: official website 2019, viewed 10 January 2019, <http://www.legislation.govt.nz/>.

Naumova, T 2012, 'The Warm Climate of New Zealand', Pryamyye investitsii, no. 6 (122), pp. 78-81, (in Russian).

The Center for Anti-Corruption Research and Initiatives of Transparency International: the official website of the autonomous non-profit organization 2019, viewed 10 January 2019, <https://www.transparency.org.ru>, (in Russian).

The First News Agency of Iraq: official website 2019, viewed 10 January 2019, <https://www.alghadpress.com>, (in Arabian).

TheWorldOnly: an Information Initiative to Promote Sustainable Development Goals: official website 2019, viewed 10 January 2019, <https://www.theworldonly.org>, (in Russian).

'UN Convention Against Corruption: from October 31, 2003' 2019, UN: official site, viewed 10 January 2019, $<$ https://www.un.org/ru/documents/decl_conv/conventions/corruption.shtml>, (in Russian). 